American Journal of Applied Sciences 8 (4): 355-358, 2011

ISSN 1546-9239

(C) 2010 Science Publications

\title{
Coordination of Series and Shunt Flexible Alternating Current Transmission Line System Devices Based Thyristor Controller for Improving Power System Stability
}

\author{
Prechanon Kumkratug \\ Division of Electrical Engineering, Faculty of Engineering at Si Racha, \\ Kasetsart University, 199 M.6, Tungsukhla, Si Racha, Chonburi, 20230, Thailand
}

\begin{abstract}
Problem statement: Thyristor Controlled Series Capacitor (TCSC) and Static Var Compensator (SVC) have been individually applied to improve stability of power system. Approach: This study presents the coordination of a TCSC and SVC for improving power system stability. The swing curves of the three phase faulted power system with various cases are tested and compared. Results: The swing curve of system without FACTS devices has undamped oscillation. The system with a TCSC or a SVC can increase damping of power system whereas the system with coordination of a TCSC and a SVC provides the best results of stability improvement Conclusion: From the simulation results, the stability of power system can be much better improved by coordination control of a TCSC and a SVC.
\end{abstract}

Key words: Power system stability, transient stability, FACTS devices, thyristor controlled, Static Var Compensator (SVC), Static Synchronous Series Compensator (SSSC), Thyristor Controlled Series Capacitor (TCSC), Single Machine Infinite Bus (SMIB), electrical power, dynamic behavior

\section{INTRODUCTION}

In modern power systems, there exists a continuous challenge to improve stability of power system. The rapid advances in power electronics area have made it possible to apply it to power system. Flexible AC Transmission system (FACTS) devices based on the rapid development of power electronics technology to improve stability of power system There are various forms of FACTS devices such as Static Synchronous Series Compensator (SSSC), Static Synchronous Compensator (STATCOM), Unified Power Flow Controller (UPFC) and Inter line Power Flow Controller (Al-Husban, 2009; Babainejad and Keypour, 2010; Ibrahim, 2009; Mohammadi et al., 2009; Nisar et al., 2008; Kumkratug, 2010; Chamsai et al., 2010).

Thyristor Controlled Series Capacitor (TCSC) and Static Var Compensator (SVC) are FACTS families. They employ Thyristor to control capacitor or reactor as shown in Fig. 1-2, respectively. TCSC is equipped in series with the line for compensating reactive power whereas SVC is equipped in shunt with the line and applied as shunt compensator (Mustafa and Magaji, 2009; Magaji and Mustafa, 2009; Zahim et al., 2009).

This study presented the coordination of a TCSC and a SVC for improving transient stability of power system. The presented mathematical model has shown that power flow with combination of a TCSC and SVC

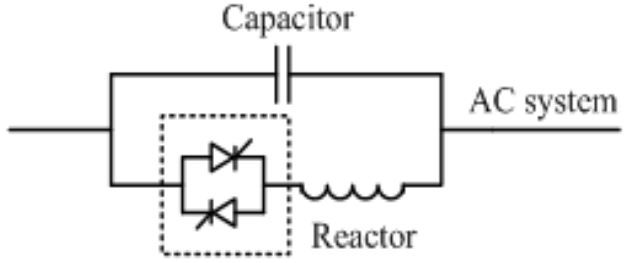

Thyristor

controller

Fig. 1: Schematic diagram of TCSC

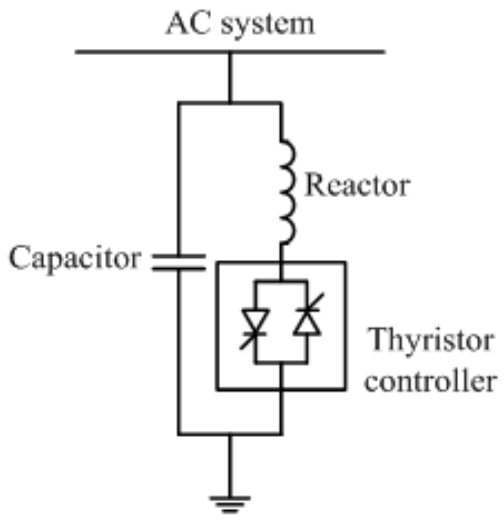

Fig. 2: Schematic diagram SVC 
can be controlled both series and shunt reactance. The simulation results are tested on Single Machine Infinite Bus (SMIB) system.

\section{MATERIALS AND METHODS}

Mathematical model: Figure $3 \mathrm{a}$ shows the single machine infinite bus stem without FACTS devices and Fig. 3b shows equivalent circuit of Fig. 1a. Here $E^{\prime}$ and $\mathrm{V}_{\mathrm{b}}$ are the generator voltage behind transient reactance and infinite bus voltage. The $X_{1}$ is the equivalent reactance from generator to bus $m$ and the $\mathrm{X}_{2}$ is the equivalent reactance from $\mathrm{m}$ to infinite bus.

The output electrical power of the system without FACTS devices is given by:

$\mathrm{P}_{\mathrm{e}}^{0}=\frac{\mathrm{E}^{\prime} \mathrm{V}_{\mathrm{b}}}{\left(\mathrm{X}_{1}+\mathrm{X}_{2}\right)} \sin \delta$

When a TCSC as shown in Fig. 1 is inserted between bus $\mathrm{m}$ and infinite bus of power system as shown in Fig. 4. The TCSC is represented by a series reactance.

The output electrical power of generator in the system with a TCSC is given by:

$\mathrm{P}_{\mathrm{e}}^{\mathrm{tcsc}}=\frac{\mathrm{E}^{\prime} \mathrm{V}_{\mathrm{b}}}{\left(\mathrm{X}_{1}+\mathrm{X}_{2}-\mathrm{X}_{\mathrm{tcsc}}\right)} \sin \delta$

Figure $5 \mathrm{~b}$ shows the equivalent circuit after stardelta conversion.

The value of the transfer reactance of the system with a SVC is given by:

$X_{\mathrm{eq}}^{\mathrm{svc}}=\mathrm{X}_{1}+\mathrm{X}_{2}+\frac{\mathrm{X}_{1} \mathrm{X}_{2}}{\mathrm{X}_{\mathrm{s}}}$

The output electrical power $\left(\mathrm{P}_{\mathrm{e}}^{\mathrm{svc}}\right)$ of the generator in the system with a SVC can be expressed as:

$\mathrm{P}_{\mathrm{e}}^{\mathrm{svc}}=\mathrm{E}_{\mathrm{q}}^{\prime} \mathrm{V}_{\mathrm{b}} \mathrm{B}_{\mathrm{eq}}^{\mathrm{svc}} \sin \delta$

Here $B_{\text {eq }}^{\text {svc }}=1 / X_{\text {eq }}^{\text {svc }}$.

This study presented the mathematical model of the system with coordination of TCSC and SVC. Figure 6a shows the equivalent circuit of the system with a TCSC and a SVC. Figure $6 \mathrm{~b}$ shows the successive equivalent circuit after star-delta conversion.

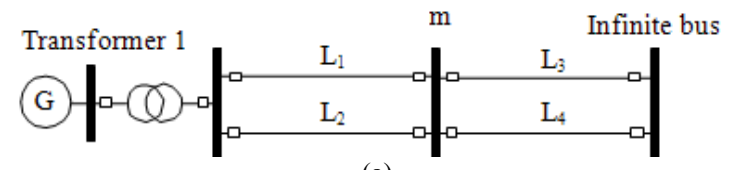

(a)

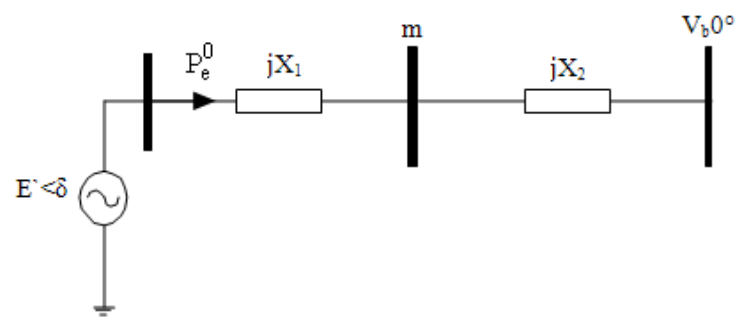

(b)

Fig. 3: Single machine infinite bus system (a) single line diagram (b) equivalent circuit

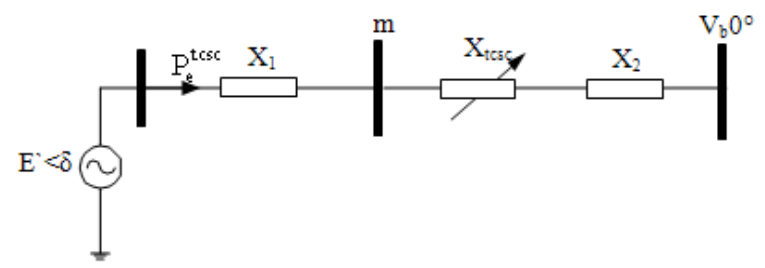

Fig. 4: Single machine infinite bus system with a TCSC (a) equivalent circuit

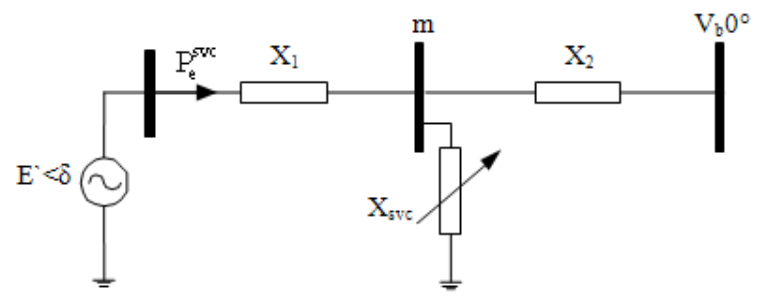

(a)

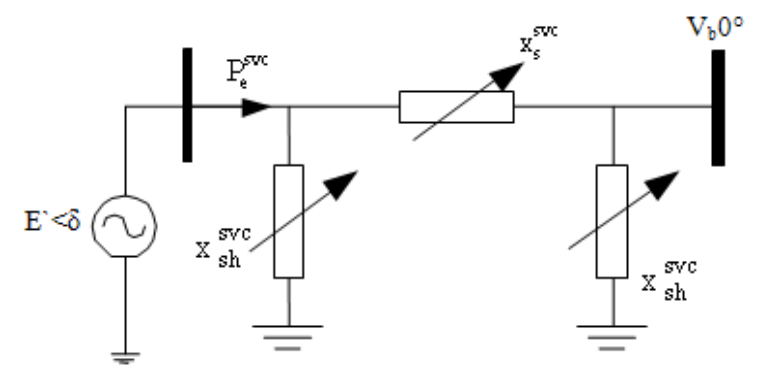

(b)

Fig. 5: Single machine infinite bus system with a SVC (a) equivalent circuit (b) equivalent circuit after star-delta transformation 


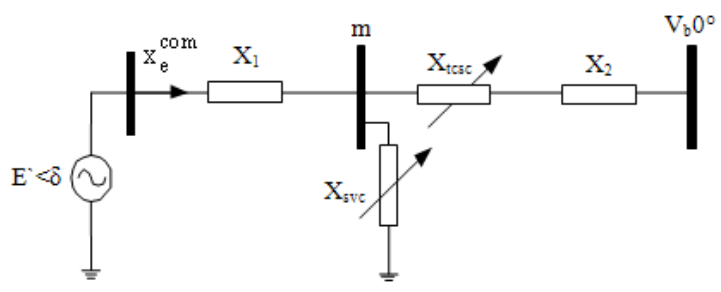

(a)

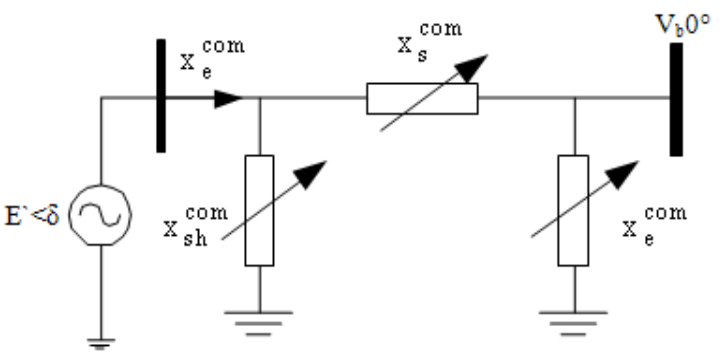

(b)

Fig. 6: Single machine infinite bus system with the combination of a TCSC and a SVC (a) equivalent circuit (b) successive equivalent circuit after star-delta transformation

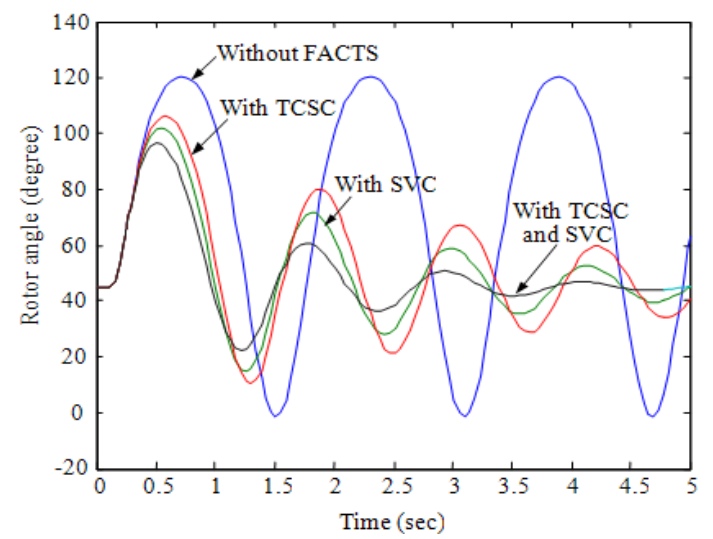

Fig. 7: Rotor angle of the system with various cases of FACTS devices

The value of the transfer reactance of the system with a TCSC and a SVC is given by:

$$
\begin{aligned}
& X_{\mathrm{eq}}^{\mathrm{com}}=\mathrm{X}_{1}+\mathrm{X}_{2}+\mathrm{X}_{\mathrm{tcsc}}+\frac{\mathrm{X}_{1}\left(\mathrm{X}_{2}+\mathrm{X}_{\mathrm{tcsc}}\right)}{\mathrm{X}_{\mathrm{s}}} \\
& =\mathrm{X}_{1}+\mathrm{X}_{2}+\mathrm{X}_{\mathrm{tcsc}}+\mathrm{B}_{\mathrm{svc}} \mathrm{X}_{1}\left(\mathrm{X}_{2}+\mathrm{X}_{\mathrm{tcsc}}\right)
\end{aligned}
$$

(The output electrical power ( $\mathrm{P}_{\mathrm{e}}^{\mathrm{com}}$ ) of the generator in the system with a TCSC and a SVC can be expressed as:

$$
\mathrm{P}_{\mathrm{e}}^{\mathrm{com}}=\mathrm{E}_{\mathrm{q}}^{\prime} \mathrm{V}_{\mathrm{b}} \mathrm{B}_{\mathrm{eq}}^{\mathrm{com}} \sin \delta
$$

Here:

$\mathrm{B}_{\mathrm{eq}}^{\mathrm{com}}=1 / \mathrm{X}_{\mathrm{eq}}^{\mathrm{com}}$

The generator dynamics, in classical model of system with a TCSC and a SVC, can be represented by following two first order differential equation:

$$
\begin{aligned}
& \dot{\delta}=\omega \\
& \dot{\omega}=\frac{1}{\mathrm{M}}\left[\mathrm{P}_{\mathrm{m}}-\mathrm{P}_{\mathrm{e}}^{\mathrm{com}}\right]
\end{aligned}
$$

Here $\delta, \omega, \mathrm{P}_{\mathrm{m}}, \mathrm{P}_{\mathrm{e}}^{\mathrm{com}}$ and $\mathrm{M}$ are the rotor angle, speed, input mechanical power, output electrical power and inertia, respectively, of the generator. Solving the eqns. 7-8 yields the variation of $\delta$ and $\omega$ that can be used to study the dynamic behavior of the generator. Equation (8) clearly indicates that the output electrical power $\left(\mathrm{P}_{\mathrm{e}}^{\mathrm{com}}\right)$ of the generator is the main factor that dictates the dynamic behavior of the generator because both $\mathrm{P}_{\mathrm{m}}$ and $\mathrm{H}$ are usually considered as constant.

Control strategy: This study uses the machine speed to control both a TCPST and a SVC. When the speed deviation is positive $(\omega>0)$, the $\mathrm{P}_{\mathrm{e}}^{\mathrm{com}}$ is increased; When the speed deviation is negative $(\omega<0)$, the $\mathrm{P}_{\mathrm{e}}^{\mathrm{com}}$ is decreased.

\section{RESULTS}

The presented mathematical model and control strategy is used to study the effect of coordination of a TCPST and SVC on transient stability improvement of the system. In all cases, it is considered that a three phase self clearing fault appears at bus $m$ and the fault is cleared without changing the network configuration. Fig. 5 shows the swing curve of the system without an TCPST for clearing time $\left(\mathrm{t}_{\mathrm{cl}}\right)=150 \mathrm{msec}$

\section{DISCUSSION}

From the results in Fig. 7, it is found that power system has undamped oscillation. The maximum and minimum rotor angles are around 120 and 0 degree, respectively. However, the damping of the system improves as the number of FACTS devices based Thyristor controllers is increased. With only a TCSC or $\mathrm{SVC}$, the maximum and minimum rotor angles are around 100 and 10 degree, respectively. With the coordination of a TCSC and SVC, the maximum and minimum rotor angles are improved to 95 and 20 degree, respectively. 


\section{CONCLUSION}

This study presented the coordination of series and shunt FACTS devices based thyristor controller for improving transient stability of power system. The Thyristor Controlled Series Capacitor (TCSC) is series FACTS devices and it is represented by series variable reactance. The Static Var Compensator (SVC) is shunt FACTS devices and it is represented by shunt variable reactance. The presented mathematical model has shown that power flow with combination of a TCSC and SVC can be controlled both series and shunt reactance. The simulation results are tested on Single Machine Infinite Bus (SMIB) system. From the simulation results, it indicates that with the coordination of a TCSC and SVC provides the best results of transient stability improvement.

\section{REFERENCES}

Al-Husban, A.N., 2009. An eigenstructure assignment for a static synchronous compensator. Am. J. Eng. Applied Sci., 2: 812-816. DOI: 10.3844/ajeassp.2009.812.816

Babainejad, S. and R. Keypour, 2010. Analysis of transient voltage stability of a variable speed wind turbine with doubly fed induction generator affected by different electrical parameters of induction generator. Trends Applied Sci. Res., 5: 267-278.

Chamsai, T., P. Jirawattana and T. Radpukdee, 2010. Sliding mode control with PID tuning technique: An application to a de servo motor position tracking control. Energy Res. J., 1: 55-61. DOI: 10.3844/erjsp.2010.55.61
Kumkratug, P., 2010. application of interline power flow controller to increase transient stability of power system. J. Comput. Sci., 6: 1490-1493. DOI: 10.3844/jcssp.2010.1484.1487

Magaji, M. and M.W. Mustafa, 2009. Optimal thyristor control series capacitor neuro-controller for damping oscillations. J. Comput. Sci., 5: 980-987. DOI: $10.3844 /$ jcssp.2009.980.987

Mohammadi, S.M.A., A.A. Gharaveisi and M. Mashinchi, 2009. A novel fast and efficient evolutionary method for optimal design of proportional integral derivative controllers for automatic voltage regulator systems. Asian J. Applied Sci., 2: 275-295.

Mustafa, M.W. and N. Magaji, 2009. Optimal location of static var compensator device for damping oscillations. Am. J. Eng. Applied Sci., 2: 353-359. DOI: 10.3844/ajeassp.2009.353.359

Nisar, M.W., Y.J. Wang and M. Elahi, 2008. Software development effort estimation using fuzzy logic - a survey. Proceedings of the 5th International Conference on Fuzzy Systems and Knowledge Discovery, Oct. 18-20, IEEE Xplore, Shandong, pp: 421-427. DOI: 10.1109/FSKD.2008.370

Zahim, S.M., M. Norainon, J.M. Shawal and R.I.R.M. Taufika, 2009. Iterative numerical method of gate turn-off thyristor: Comparative study between $\mathrm{Si}$ and SiC. Am. J. Eng. Applied Sci., 2: 446-450. DOI: 10.3844/ajeassp.2009.446.450 